\title{
AÇÃO COLETIVA À ESCALA INDIVIDUAL E LOCAL Perfis e retratos sociológicos
}

\author{
Nuno Nunes \\ Instituto Universitário de Lisboa (ISCTE-IUL), Centro de Investigação e Estudos de Sociologia \\ (CIES), Lisboa, Portugal \\ Rita Ávila Cachado \\ Instituto Universitário de Lisboa (ISCTE-IUL), Centro de Investigação e Estudos de Sociologia \\ (CIES), Lisboa, Portugal

\section{Otávio Raposo} \\ Instituto Universitário de Lisboa (ISCTE-IUL), Centro de Investigação e Estudos de Sociologia \\ (CIES), Lisboa, Portugal
}

\section{Daniela Ferreira}

Instituto Universitário de Lisboa (ISCTE-IUL), Centro de Investigação e Estudos de Sociologia (CIES), Lisboa, Portugal

\section{Renato Miguel do Carmo}

Instituto Universitário de Lisboa (ISCTE-IUL), Centro de Investigação e Estudos de Sociologia (CIES), Lisboa, Portugal

\begin{abstract}
Resumo Este artigo analisa as disposições para a ação coletiva, sobretudo no que toca às escalas individual e local. Focamo-nos na pluralidade das situações individuais, atentando ao papel dos contextos locais para a maior ou menor incorporação de um "habitus militante". Realizaram-se entrevistas aprofundadas a 15 indivíduos pertencentes a nove agregados familiares residentes em três concelhos da área metropolitana de Lisboa, a partir das quais se construíram perfis e retratos sociológicos que salientam a relevância das socializações, das sociabilidades e do envolvimento em atores coletivos nas disposições para a ação coletiva.
\end{abstract}

Palavras-chave ação coletiva, escala individual, escala local, retratos sociológicos.

Abstract This article analyzes the dispositions towards collective action, especially in regards to the local and individual scales. We focus mainly on the plurality of the individual situations, paying attention to the role of the local contexts to the greater or lesser incorporation of a radical habitus. In depth interviews were done to 15 individuals belonging to nine households living in three municipalities of the Lisbon Metropolitan Area, from which were built profiles and sociological portraits which salient the relevance of socializations, sociability and the involvement in collective actors in the dispositions for the collective action.

$\underline{\text { Keywords }}$ collective action, individual scale, local scale, sociological portraits.

Résumé Cet article analyse les dispositions pour l'action collective, surtout en ce qui concerne les échelles individuelle et locale. On met en évidence la pluralité des situations individuelles, en faisant attention au rôle des contextes locaux pour la plus grande ou la plus petite incorporation d'un habitus militant. On a fait des interviews approfondies avec 15 individus qui appartiennent à neufs familles qui habitent trois départements de la zone métropolitaine de Lisbonne et, à partir de celles-ci on a construit des profils et des portraits sociologiques qui relèvent les socialisations, les sociabilités et l'engagement dans des acteurs collectifs dans les dispositions pour l'action collective.

Mots-clés action collective, échelle individuelle, échelle locale, portraits sociologiques. 
Resumen Este artículo analiza las disposiciones para la acción colectiva, sobretodo a escalas individual y local Nos enfocamos en la pluralidad de las situaciones individuales y considerando el rol de los contextos locales para una mayor o menor incorporación de un habitus militante. Se realizaron entrevistas a profundidad a 15 individuos de nueve hogares residentes en tres ayuntamientos del Área Metropolitana de Lisboa, a partir de las cuales se construyeron perfiles y retratos sociológicos que evidencian la relevancia de las socializaciones, de las sociabilidades y del envolvimiento en actores colectivos en las disposiciones para la acción colectiva.

\section{Introdução}

É relevante analisar a ação coletiva à escala individual, isto é, a partir dos seus protagonistas e em contextos locais de interação? ${ }^{1}$ Na maioria das análises sobre a ação coletiva, os movimentos sociais e as suas organizações constituem as principais unidades de análise, constituindo-se naturalmente como os seus objetos de estudo de partida. Contudo, são os indivíduos que, através da conjugação de múltiplas ações assumidas coletivamente, formam essas mesmas organizações e movimentos sociais. A ação coletiva pode, precisamente, ser estudada a partir da mobilização ativa dos indivíduos, justificando-se que as práticas dessa ação coletiva possam ser uma esfera de observação microssocial enquanto ação individual.

No âmbito de uma sociologia da pluralidade disposicional e contextual, proposta por Lahire (2003 e 2005), analisa-se a escala individual da ação coletiva, procurando não perder de vista, em primeiro lugar, os contextos e as condições sociais dos indivíduos e, em segundo, a decifração das suas disposições sociais para a ação coletiva. Analisam-se os fatores subjetivos e os fatores objetivos presentes na estruturação da ação coletiva, evidenciados nas trajetórias biográficas de protagonistas dessa ação.

No entanto, consideramos que a perspetiva de ancoragem à escala individual deverá ser complementada por outras dimensões tão relevantes para a incorporação de práticas regulares de ação coletiva como são as formas de socialização e de interação local.

Assim o objetivo deste artigo consiste em compreender a ação coletiva a partir de uma análise qualitativa, que inclui a exploração do dispositivo metodológico dos retratos sociológicos de três protagonistas de ação coletiva residentes na área metropolitana de Lisboa (AML). Trata-se de indivíduos comprometidos em diferentes esferas da ação coletiva, nomeadamente a sindical, a política, a associativa e a cultural-artística, nas quais as socializações e os contextos de interação local foram fundamentais para a sua sedimentação.

$\mathrm{O}$ artigo organiza-se da seguinte forma: iremos, num primeiro momento, discutir teoricamente a ação coletiva incidindo na escala individual e local. Posteriormente apresentaremos uma análise transversal do material qualitativo,

1 Este artigo tem por base o projeto de investigação “Localways - Trajetos de Sustentabilidade Local: Mobilidade, Capital Social e Desigualdade", financiado pela FCT (PTDC/ATP-EUR/5023/2012). 
identificando perfis distintos de práticas de ação coletiva. Seguidamente concentramo-nos em três indivíduos e seus retratos sociológicos de adesão à ação coletiva.

\section{A ação coletiva: da teoria ao indivíduo}

A ação coletiva nas sociedades contemporâneas assume diversas modalidades, sendo por isso multidimensional. Para a sua efetivação, enquanto consagração do exercício de direitos sociais, económicos, políticos e culturais, um conjunto alargado de constrangimentos socioestruturais configuram uma ação coletiva fractal e desigual (Nunes, 2013a). Os direitos de cidadania não são exercidos de igual forma por todos os indivíduos nas sociedades contemporâneas (Frazer, 2008). Neste sentido, uma maior capacitação para a ação coletiva constitui uma questão relevante em democracias consolidadas orientadas para uma maior igualdade e justiça social.

Assumindo várias designações transmutáveis, a ação coletiva ocupa um lugar central ao longo das teorias sociológicas, desde os "clássicos" até às teorias contemporâneas (Martin, 2015). São múltiplos os enfoques relativamente à ação coletiva, desde análises mais estruturalistas até às mais focadas nas identidades. Nos vários paradigmas e correntes teóricas que se debruçam sobre a ação coletiva, é variável a presença da escala individual (Van Stekelenburg e Klandermans, 2007; Kelly e Breinlinger, 1996).

Nas teorias da mobilização dos recursos e da ação racional, a ação coletiva é essencialmente caracterizada enquanto ação instrumental e centrada do ponto de vista da capacidade organizativa da obtenção de recursos (Edwards e McCarthy, 2004; McCarthy e Zald, 2001). Segundo este paradigma, os indivíduos avaliam estrategicamente a sua participação e adesão à ação coletiva em função dos seus interesses individuais. A noção de interesse enquanto explicação integrada da ação social, bem como os pressupostos desenvolvidos à volta do "dilema do prisioneiro" (Olson, 1998) constituem os seus argumentos teóricos basilares.

Por seu turno, as teorias dos novos movimentos sociais destacam a emergência de novas arenas de conflito e a proliferação e diversificação de movimentos de novo tipo, ligados sobretudo a categorias sociais de cariz identitário (Touraine, 1998; Wieviorka, 2012). Em contraponto à racionalização de caráter instrumental definidora dos sistemas como o estado, o económico e o político, os indivíduos possuem a capacidade de formar espaços sociais e políticos autónomos (Burawoy, 2015; Castells, 2012), reivindicativos de "novas gramáticas" para a vida social - o que Habermas (1989) intitula "mundo da vida".

As teorias dos movimentos sociais e da ação coletiva poderão ser enriquecidas com a incorporação da teoria da prática (Bourdieu, 1997; Nunes, 2013b). Crossley (2002) é um dos principais autores contemporâneos que tem sabido explorar a profundidade do conceito de habitus desenvolvido por Bourdieu. A conceção do habitus encoraja o estudo dos movimentos sociais, considerados como uma construção coletiva de indivíduos dotados de diferentes intencionalidades e estratégias 
sociais, indivíduos que, enquanto construtores ativos de ação coletiva, incorporam esquemas de perceção social, recursos e modos de agir derivados da sua incrustação no mundo social. São indivíduos com histórias pessoais, singulares, mas que se inscrevem, igualmente, nas histórias coletivas mais amplas, das quais fazem parte com a sua trajetória de vida (Crossley, 2002).

Crossley sugere o conceito de "habitus militante" (Crossley, 2003) que, associado à biografia individual inscrita na estrutura social, incorpora, objetivamente, os processos históricos e as formas de ação coletiva e, subjetivamente, os eventos vividos. Crossley refere-se ao "habitus militante" para demonstrar a influência não apenas dos constrangimentos estruturais, da posição social e das socializações primárias na adesão à ação coletiva, mas procurando igualmente explicar os efeitos socializadores (secundários) que a própria ação coletiva poderá ter sobre os indivíduos, ou seja, como ela poderá incrustar-se nos modos de vida dos indivíduos, exercendo assim influência sobre os seus esquemas de apreciação, de representação e de ação do seu mundo social.

A assunção de determinados reportórios de ação coletiva (Tilly, 2006) reflete as opções dos indivíduos nas possibilidades de ação coletiva, ao mesmo tempo que exprime as trajetórias biográficas específicas dos indivíduos em causa. Tais trajetórias são um fator de estruturação social, igualmente visível no plano das representações e valores que os indivíduos transportam consigo.

Lahire constitui um autor-chave para a construção de uma teoria disposicional da ação coletiva (Lahire, 2003; Mouzelis, 2008), capaz de analisar a escala individual da ação coletiva - nomeadamente a sua pluralidade disposicional e contextual - e respetivas lógicas de interação social (Costa, 1995, 1999). É a partir da pluralidade do habitus (Costa, 2007), enquanto sistema de disposições aberto à diversidade das orientações da ação que os indivíduos se posicionam perante a ação coletiva. As disposições para a ação coletiva só podem ser convenientemente problematizadas contemplando as variáveis de natureza biográfica resultantes das trajetórias coletivas e pessoais dos indivíduos (Giugni, 2004; McAdam, 1999).

As biografias tornam-se cada vez mais complexas, desenrolando-se dentro de um campo diverso mas finito de possibilidades (Velho, 1994). No âmbito de uma sociologia da pluralidade disposicional e contextual, é possível a apreensão da variação disposicional, consoante as esferas de socialização estruturais e culturais que caracterizam uma determinada trajetória de vida. Enquadrar analiticamente a complexidade interna e subjetiva de cada ator implica abordar a singularidade individual a partir de formas diversificadas de socialização produzidas na interseção de diferentes esferas e forças sociais (Lopes, 2012).

Estas tendem a ser estruturadas em determinados contextos sociais e em específicos "quadros de interação" (Costa, 1999), nos quais se inscreve a participação individual nas dinâmicas da ação coletiva. São os "quadros de interação" que transportam sentidos e identidades (plurais) para a ação coletiva dos agentes (ou ausência dela), construídos a partir de parâmetros estruturais, institucionais, disposicionais, relacionais e simbólicos, e mobilizados no decurso da interação social.

O âmbito da ação e da sociabilidade local representa uma esfera importante e por vezes decisiva para a dinamização e reprodução das práticas de mobilização 
cívica e de pertença a associações ou a outros atores coletivos (Carmo, 2011). Em muitos casos são os fatores que aliam a proximidade societal com a proximidade local aqueles que mais contribuem para a incorporação de experiências marcantes com influência decisiva nos trajetos e nas disposições sociais.

Entender as práticas da ação coletiva, à escala individual e local, implica ter em conta os elementos situacionais e os seus efeitos, não deriváveis exclusivamente nem da posição social nem das disposições sociais dos atores, numa ordem social que se alcança pelos próprios processos da interação social. As situações sociais no quotidiano não são um terreno neutro onde os agentes aplicam meios para atingir determinados fins preestabelecidos, mas sim contextos sociais estratégicos geradores de intencionalidades singulares e coletivas múltiplas, entre elas a ação coletiva.

Verificamos, por intermédio da análise qualitativa desenvolvida, que os meios e os agentes de socialização local, assim como os contextos locais de sociabilidade, são fundamentais enquanto fatores disposicionais propiciadores de formas intensas e regulares de ação coletiva. Estes podem ser decisivos para a incorporação de um "habitus militante", no qual a ação coletiva não é resultado de uma simples agregação dos vários interesses pessoais, mas contextualizada e mediada por atores coletivos ancorados em contextos locais e em quadros de interação específicos.

\section{Metodologia}

A análise sociológica contemporânea depara-se com a necessidade de aprofundar as suas possibilidades metodológicas relativamente ao estudo da ação coletiva (Klandermans e Staggenborg, 2002) e a ancoragem à escala individual dessa ação possibilita a interpenetração sobre determinados contextos locais e/ou regionais, atores coletivos, movimentos sociais, instituições e processos históricos (Coelho, 2012; Klandermans e Roggeband, 2007).

A grande inovação de Lahire consiste, precisamente, numa mudança ao nível do objeto de estudo, quando analisa indivíduos singulares, apoiando-se na teoria-metodologia dos retratos sociológicos, construídos com base em entrevistas aprofundadas, reconstituindo as disposições incrustadas em cada indivíduo e os diferentes quadros de socialização e de experiências por que estes passam (Lahire, 2002).

O projeto "Localways - Trajetos de Sustentabilidade Local: Mobilidade, Capital Social e Desigualdade" desenvolveu-se tendo por base duas vertentes metodológicas complementares. A primeira de caráter quantitativo resultou da conceção e aplicação de um inquérito por questionário realizado a 1500 residentes na área metropolitana de Lisboa (AML) com idade igual ou superior a 18 anos, abrangendo um total de 75 freguesias. A segunda vertente, de caráter qualitativo, concretizou-se na realização de entrevistas biográficas de cariz semidiretivo a 15 indivíduos pertencentes a nove agregados familiares. Estes distribuem-se por três municípios da AML selecionados como estudos de caso do projeto: Oeiras, Odivelas 
e Alcochete. É sob esta segunda vertente do projeto que a nossa análise empírica incide.

Em relação aos agregados familiares, a seleção assentou em quatro critérios: (i) composição interna do agregado; (ii) escolaridade; (iii) faixa etária; (iv) características territoriais da AML. Estes critérios permitiram-nos obter uma diversidade de agregados quanto ao seu nível de qualificação que, por sua vez, nos remete para famílias com mais ou menos rendimentos. Por outro lado, a faixa etária garante a diversidade no confronto entre gerações. O objetivo do projeto "Localways" foi procurar obter um leque variado de agregados familiares que pudesse retratar padrões comuns.

O guião, aplicado em todas as entrevistas realizadas, baseou-se numa linha temporal, partindo do passado até ao futuro, de modo a podermos entender a trajetória de vida do indivíduo bem como os seus planos e projetos. O guião procurou captar o espaço-tempo quotidiano, nomeadamente a relação entre o agregado e o meio que o rodeia, a sua gestão entre o trabalho e o lazer, as sociabilidades, os consumos, a mobilidade e a existência ou não de práticas de ação coletiva.

Do universo dos entrevistados foram identificados determinados perfis de ação coletiva, convergentes com a vertente quantitativa do projeto de investigação. O dispositivo metodológico do retrato sociológico exige uma complexidade (Costa, Lopes e Caetano, 2014; Lopes 2014) que nem sempre foi conseguida com todos os nossos interlocutores. Ainda assim, alguns casos foram bastante aprofundados: num caso realizámos três entrevistas; em dois casos realizámos duas entrevistas uma delas com um total de sete horas - e em cinco casos realizámos entrevistas a vários elementos do mesmo agregado familiar. Selecionámos três indivíduos com saliente ação coletiva à escala local, concretamente Luís, Maria e David (pseudónimos), estudos de caso que nos garantiram uma adequada aplicação do dispositivo metodológico dos retratos sociológicos.

Adicionalmente, realizámos visitas de terreno de carácter etnográfico às localidades e contextos específicos dos agregados, com registo em diário, permitindo um aprofundamento do conhecimento de cada caso.

\section{Perfis de ação coletiva na área metropolitana de Lisboa}

Procura-se caracterizar, de forma geral, a adesão e a não adesão a práticas de ação coletiva tendo como base as disposições dos indivíduos e os contextos locais de socialização e de interação social. A análise baseou-se nas entrevistas realizadas aos indivíduos dos agregados familiares participantes no projeto de investigação "Localways".

A maioria dos indivíduos entrevistados já teve na sua vida algum tipo de prática de ação coletiva. Pela análise das entrevistas, podemos definir três perfis de adesão a práticas de ação coletiva. Por um lado, existem os indivíduos que ao longo da sua trajetória tiveram práticas de ação coletiva e que continuam atualmente a ter (o qual designamos perfil 1). De seguida, encontram-se aqueles que têm intermitentemente práticas de ação coletiva (perfil 2). Por último, identificam-se os que (já) não têm tais práticas num período de tempo considerável (perfil 3). 
Pretende-se compreender o que leva à adesão a práticas de ação coletiva de modo permanente ou intermitente/pontual, bem como as razões apontadas por aqueles que deixaram de as ter ou que nunca as tiveram.

Comecemos pelo perfil 1, os indivíduos que continuamente aderem a práticas de ação coletiva. Neste grupo encontramos a Maria (agregado 4, Odivelas), os irmãos David e Mário (agregado 7, Odivelas), o Gonçalo (agregado 8, Odivelas) e o Luís (agregado 9, Alcochete).

A adesão a atores coletivos constitui uma condição para uma contínua participação cívica por parte destes indivíduos. Predomina a adesão a algum tipo de associação e/ou fazem parte de um partido político, ou pelo menos são simpatizantes, e por isso mantêm algum contacto e participam em eventos coletivos.

As disposições para a ação coletiva por parte de Gonçalo iniciaram-se cedo na sua vida, sobretudo através da perceção das condições de vida e laborais e das desigualdades de tratamento entre as classes sociais em Trás-os-Montes. Como refere:

O meu pai [...] foi trabalhar ao preço da uva mijona, ganhava 1000 escudos. É interessante porque aos outros dava 1700 escudos e ao meu pai só dava 1000. Porque o meu pai tinha 17 filhos, e recebia abono, e eles descontavam o abono. Eu até, quando tinha 10 anos, apercebi-me. Por isso é que tenho esta minha revolta. O patrão [...] estava a tirar-lhe 700 escudos! Porque o resto devia ser segurança social, por isso é que me deixou assim. [Gonçalo, 54 anos, Odivelas, entrevista 21/10/2014]

As condições socioeconómicas mais desfavorecidas marcam a vida de Gonçalo, mesmo durante a sua experiência de presidente de uma associação. O relato seguinte refere-se a uma deslocação de jovens atletas da coletividade:

Cheguei a ter uma equipa de 47 atletas [...]. O meu subsídio de férias ou de natal, muitas vezes era para calçar os miúdos de ténis. Uma vez numa corrida em Torres Vedras havia uns miúdos sem ténis. Cheguei cinco minutos antes da prova começar. Quando trago os ténis aos miúdos foi uma festa, um deles ficou em primeiro lugar, com uma satisfação! Então ia chegar a casa e dizer aos pais que não correram?! [Gonçalo, 54 anos, Odivelas, entrevista 02/12/2014]

Neste perfil são vincadas as disposições ativadas para a justiça social e bem comum, à volta do papel destes indivíduos enquanto cidadãos. Observa-se um gosto pessoal por áreas de intervenção que se manifesta na participação em associações ou grupos de voluntariado.

As sociabilidades, ou seja, a rede de contactos e a proximidade entre pessoas, é um dos fatores que mais pesa para a existência de práticas de ação coletiva neste perfil. Isso sobressai, por exemplo na entrevista ao Luís (agregado 9, Alcochete):

Vou à vila e conheço as pessoas quase todas. Também derivado, se calhar, ao meu trabalho, ando aí de chofer. Como faço parte daqui da coletividade, os papéis e quotas que passam pelas mãos, conheço toda a gente a bem dizer. [Luís, 60 anos, Alcochete, entrevista 26/01/2015] 
O Mário (agregado 7, Odivelas) foi influenciado pelo seu pai e pelo irmão no interesse pelas questões políticas, pela participação em reuniões e debates:

Na verdade foi através do meu pai que entrei no Bloco. Então foi um pouco por aí que eu comecei a ir às coisas e a conhecer a malta. [Mário, 19 anos, Odivelas, entrevista 22/10/2014]

A relação com o espaço territorial onde estes indivíduos residem, nomeadamente a sua identidade local, é sem dúvida outro fator construtor de disposições para a ação coletiva. O David (agregado 7), o Gonçalo (agregado 8) e o Luís (agregado 9) salientam um vincado sentimento de pertença ao local onde vivem. Mais singular é o caso do David que, apesar de viver atualmente em Odivelas, é na Damaia que sente as suas origens e por isso a sua ação coletiva ainda ocorre nesta localidade.

Em síntese, neste perfil 1 verificam-se cinco fatores interligados entre si, potenciadores de práticas de ação coletiva: (i) adesão a atores coletivos (partidos, associações e sindicatos); (ii) disposições perante as desigualdades e injustiças sociais; (iii) aspirações sociais conjugadas com gostos pessoais; (iv) redes de contactos e sociabilidades; e (v) identidades locais.

No grupo dos indivíduos pontualmente ativos (perfil 2), inclui-se a Cristina (agregado 3, Oeiras), a Bárbara (agregado 2, Oeiras) e a Paula (agregado 7, Odivelas). A criação deste perfil tornou-se evidente porque as práticas de ação coletiva destes indivíduos ao longo da sua trajetória de vida sempre se manifestaram através de iniciativas pontuais e de curta duração. Embora os permanentemente ativos também refiram este tipo de iniciativas, este grupo de pessoas apenas indica iniciativas deste caráter. Referimo-nos sobretudo a manifestações, petições ou outras formas de protesto. As disposições associadas a estas práticas de ação coletiva prendem-se essencialmente com o sentimento de descontentamento e de revolta destes indivíduos perante episódios do seu quotidiano. Isto faz com que pontualmente protestem através dos meios disponíveis no seu entorno. Como refere Bárbara:

Necessidade de reclamar? Há um "baixo-assinado" sobre o toque dos bombeiros ao meio dia. Queriam acabar com isso e os bombeiros querem manter e eu assinei. De uma maneira geral não me manifesto, mas quando há oportunidade, sim. [Bárbara, 45 anos, Oeiras, entrevista 02/05/2014]

Relativamente aos indivíduos que não referem no momento da(s) entrevista(s) estar ativamente a participar em qualquer prática de ação coletiva (perfil 3), identificou-se a Patrícia (agregado 1, Oeiras), a Inês (agregado 4, Odivelas), a Joana (agregado 5, Alcochete) e a Natália (agregado 9, Alcochete). A acrescentar a estes, surgem os casos do Jaime (agregado 5, Alcochete) e da Tânia (agregado 6), que desenvolveram ação coletiva no passado.

O Jaime aponta como principal razão para a sua atual ausência de ação coletiva as alterações na sua vida pessoal, como a mudança de local de residência e a passagem do seu estado civil de solteiro para casado. A mudança de casa para outro concelho (de Setúbal para Alcochete) provocou uma perda acentuada da rede de 
relações que estavam associadas à sua militância política. No entanto, o que refere como razão principal para não permanecer no partido a que anteriormente se sentia ligado foi a progressiva falta de identificação ideológica.

O caso de Tânia parece sugerir uma não atividade que decorre de fatores pessoais pontuais e de fatores externos como a crise económica e a respetiva dificuldade em obter financiamentos para projetos locais. No momento da entrevista, a Tânia encontrava-se a iniciar uma atividade laboral após um período de desemprego, donde não se revia na possibilidade de participação mais ativa.

Apesar de a Patrícia ter uma mobilidade condicionada por ser paraplégica, reconhece que sempre teve poucas relações de vizinhança e mesmo de amizade, o que faz com que nunca tenha aderido a iniciativas de ação coletiva. Além disso, o trabalho em restaurantes ocupou um lugar monopolizador no seu dia a dia, a par da gestão doméstica, não lhe restando tempo, sobretudo no passado, para outras atividades. A ausência de práticas de ação coletiva associa-se a uma limitada rede de contactos e de sociabilidades, o que reforça a ideia contrária veiculada por quem participa ou participou ativamente. Como refere:

Tenho muito tempo livre, mas como tenho muita dificuldade em andar, ocupo-o a dar uma voltinha de carro, tenho um carro adaptado. Tenho mesmo de andar de carro. [...] Não tenho amigas. [...] é só uma ou duas senhoras. [Patrícia, 58 anos, Odivelas, entrevista 17/04/2014]

Em relação à Joana, a sua atividade enquanto professora, artista, estudante e mãe consome o seu tempo. Embora tenha atividade profissional fora de casa e ao mesmo tempo estude, a dedicação à casa toma particular relevância neste caso. Trata-se de uma pessoa centrada na sua habitação e em como esta pode proporcionar bem-estar a todo o agregado. Além das funções familiares, a casa desempenha ainda o papel de lugar onde desenvolve a sua atividade artística especializada (tem um ateliê anexo à casa). É notório o quanto a habitação tem um papel central na sua vida, não lhe deixando muito tempo para outro tipo de iniciativas.

No caso da Joana, não é a falta de rede de contatos e sociabilidades que se destaca enquanto fator para a não participação coletiva, mas sim o tempo disponível. Ainda assim, é de referir que a Joana, face a situações que se ligam com a sua casa ou a família, como situações pontuais de desrespeito de regras pelos vizinhos ou situações escolares, age individualmente tentando resolver a situação através de pedidos formais de esclarecimento junto das autoridades competentes. Não podemos dizer que a Joana não tem atividade reivindicativa, mas ela não se verifica à escala coletiva.

\section{Retratos de ação coletiva à escala individual e local}

Caracterizados os principais perfis, escolhemos três entrevistados do perfil 1 que desenvolvem práticas de ação coletiva à escala local, mobilizando para o efeito a exploração do dispositivo metodológico dos retratos sociológicos. Começamos 
com o Luís, com um longo e rico percurso de vida, pautado de dificuldades socioeconómicas e de resistência às adversidades, e com ligação contínua ao associativismo popular; seguidamente apresentamos a Maria, "nostálgica" do 25 de Abril, primeiramente com um percurso profissional acompanhado pelo sindicalismo e depois uma vincada participação ao nível local; e finalmente apresentamos o David, um jovem preocupado com a crise económica e que tem exercido participação cívica através das escolas por onde andou e por via da militância política e da atividade cultural.

\section{A dedicação ao associativismo popular por parte de Luís}

O estudo de caso de Luís retrata a vida de alguém que vem do Alentejo para a Margem Sul do Tejo e que é marcado pelo 25 de Abril e pela reforma agrária, em que o pai participou, o que configura um contexto sociopolítico importante para o seu envolvimento no associativismo. Como refere:

O meu pai era uma pessoa muito ativa, ainda fez parte da direção lá da Casa do Povo e daquelas coisas. Depois quando se deu o 25 de Abril e se criou a reforma agrária o meu pai fez logo parte daquilo e eu também [...]. [Luís, 60 anos, Alcochete, entrevista 04/12/2014]

Luís nasce na aldeia de Brotas, concelho de Mora, no Alentejo, em 1954. Fez a quarta classe e trabalhou desde menino a guardar gado, em cozinhas, na apanha da azeitona, na tosquia das ovelhas, espelhando o trabalho sazonal com grande abrangência entre os alentejanos que, com baixos salários e em condições laborais difíceis, assim trabalharam até ao 25 de Abril. Além da participação do pai na reforma agrária, também ele tem um episódio que recorda muitas vezes, e que retrata a sensação de injustiça relativamente ao exercício do poder das autoridades sobre as populações que lutavam pela melhoria das condições de vida:

Quando foi a primeira propriedade, o Lobo do Paço, estava lá eu e a minha mulher. Eles foram com a GNR, bateram nas pessoas. [...] A guarda estava do lado de lá da ribeira e nós estávamos do lado de cá e eles deram ordem para a gente ir embora. E eu digo para a minha mulher: "Isto vai dar porrada." Aquilo era arroz de um lado e canteiros do outro lado da estrada. Quando eles dão em avançar, digo para a minha mulher: "Não te metas na estrada! Tu foge para os canteiros do arroz." E o arroz, aquilo tem uns combros grandes, e os cavalos não podem andar lá em cima, escorregam. Eles vão dar porrada e a gente vai fugir. "Tu foges para os canteiros de arroz, não vais para a estrada." Quem se meteu na estrada apanhou porrada. Quem se meteu no arroz safou-se. [Luís, 60 anos, Alcochete, entrevista 04/12/2014]

Luís casou com 19 anos e decide, com a mulher, rumar à Grande Lisboa para melhorar as condições de vida. É fácil perceber: se num momento, no Alentejo, Luís ganhava quatro mil escudos, pouco depois de chegar a Lisboa passa a ganhar o dobro. A esposa Ofélia começa por trabalhar numa fábrica de flores no Montijo, e 
depois na seca do bacalhau em Alcochete, que deixou quando o negócio faliu, em 2001. Luís envereda na Rodoviária Nacional, atual Transportes Sul do Tejo, onde começa por ser cobrador e depois passa a motorista, profissão que continua a exercer. Nos primeiros quatro anos vivem no Montijo e depois compram casa em Alcochete, no concelho vizinho, onde ainda residem, perto das duas filhas, que depois de adultas continuam a morar no município. Luís aprofundou a sua ação coletiva, desde que começou a trabalhar na empresa de transportes onde se sindicalizou, inscrevendo-se e participando na comissão de trabalhadores e no Sindicato dos Rodoviários de Setúbal (Festru):

Fui tudo. Primeiro fui delegado sindical. 1976 foi quando fui para ali. Mais ou menos em 1980 fui da comissão de trabalhadores, fui delegado sindical e fui dirigente sindical. [Luís, 60 anos, Alcochete, entrevista 04/12/2014]

Ao ir morar para Alcochete, associou-se a uma coletividade com grande inserção local, de cariz popular, voltada para o desporto e para as sociabilidades. Luís exerceu vários cargos dirigentes e mantém uma forte colaboração e participação na gestão da coletividade, manifestando grande orgulho na sua associação:

Não tem dívidas. Não deve nada a ninguém. Pode ser publicado, escrito. Temos muitos atletas, mas antigamente eram geridos de uma maneira e agora são doutra. Porque a fartura traz tudo e a crise traz pouco. Tínhamos atletismo, mas o atletismo morreu a nível nacional. Vira-se para outras modalidades. Também não havia o karaté e hoje existe. Também não havia o ténis. Hoje há. Ainda este fim de semana houve um torneio, organizado pela sociedade de ténis, vieram atletas de todo o lado. [Luís, 60 anos, Alcochete, entrevista 04/12/2014]

Mas importa voltar ao momento de entrada na coletividade. A proximidade com outros indivíduos que provêm da mesma zona de origem terá tido influência no reforço da ação coletiva:

Havia um rapaz que é de Mora. Nessa altura ele fazia parte da direção e eu já era amigo dele lá e ele convidou-me para fazer parte dos corpos gerentes. Aceitei, depois fui indo, fui indo. [Luís, 60 anos, Alcochete, entrevista 04/12/2014]

Também para Luís a manutenção da participação local e, em termos gerais, a insistência na ação coletiva associa-se às sociabilidades que esta potencia. $O$ seguinte excerto espelha esta situação:

Enquanto a gente não tiver uma coletividade, uma casa que seja, onde a gente possa reunir e conversar e enfim, para mim não tem aquela coisa. [Luís, 60 anos, Alcochete, entrevista 04/12/2014] 
Maria: não parar de participar

A Maria é filha do baby boom do pós-guerra. Começou a vida no Algarve e, com o pai bancário, mudava frequentemente de residência naquele distrito. A experiência de mudança mais marcante foi um período em Angola, entre os 10 e os 12 anos. Termina o liceu no Algarve e ruma à AML para continuar os estudos e, nesse sentido, obter uma autonomia precoce para uma jovem mulher nos anos 60. Assim, chegada ao 25 de Abril, não hesita em participar nas lutas que surgiram na sua trajetória. Como era professora do ensino pré-primário, ingressou na lista dos primeiros membros da federação sindical Fenprof e não abandonou a atividade sindical, embora os tempos mais ativos tenham sido no período revolucionário:

A memória dos portugueses é muito curta, mas quem passou por ele não se esquece. Subi várias vezes determinadas ruas a correr, escondi-me várias vezes em igrejas... [Maria, 65 anos, Odivelas, entrevista 05/05/2014]

As sociabilidades iniciadas antes do 25 de Abril, desde a adolescência no Algarve até ao contexto do "período revolucionário em curso" (PREC) passando pelos anos iniciais da atividade laboral, continuam nos dias de hoje:

\begin{abstract}
Mantenho os amigos e é uma longa história que mantemos juntos. Quando viemos para cá, estávamos sem família, por isso no dia a dia acompanhávamo-nos. Só não saio mais com eles porque estamos dispersos. Acho que a minha geração teve lutas conjuntas, e depois sentimos essa afetividade. [Maria, 65 anos, Odivelas, entrevista 05/05/2014]
\end{abstract}

Quando se reformou há alguns anos, o facto de Odivelas ter ganho centralidade urbana foi importante para manter uma vida ativa. Maria refere a chegada do metro ao concelho em 2007 e a autonomia de Odivelas enquanto concelho relativamente a Loures, como fatores centrais do desenvolvimento hoje sentido por ela e pela família em geral. Aliás, antes de o metro chegar, Maria demorava mais de uma hora para realizar um trajeto que, sem trânsito, levaria 10 minutos. Durante a maior parte do seu percurso laboral, o tempo ocupado pelo trajeto duplo casa-trabalho e a vida familiar com filhos pequenos, impedia-a de realizar mais atividades de lazer e de participação cívica:

O sindicato era sobretudo enquanto sindicalizada de base. Outras atividades não tinha porque não tinha disponibilidade. Ainda fui ver os horários da piscina, mas depois ao fim do dia havia a casa, os filhos [...] E quando entrava em casa, tirava os sapatos e já não conseguia sair outra vez. [Maria, 65 anos, Odivelas, entrevista 05/05/2014]

Apenas retoma atividades de lazer e outras com a chegada da aposentação, que por sua vez é contemporânea do ganho de centralidade e potencial de mobilidade para os residentes do concelho onde reside. 
O seu percurso, no início da vida adulta e após a reforma, retrata uma história de participação cidadã bastante recheada. Começou por ser das primeiras a inscrever-se na Fenprof e esteve no PREC em grande atividade sindical. Essa experiência foi marcante. Hoje em dia, o facto de os filhos estarem crescidos contribui, de resto, para poder ocupar o tempo como quer: "Se houver um projeto, vou e faço e partici$\mathrm{po}^{\prime \prime}$, refere, para resumir a sua participação enquanto sócia ativa de duas associações, aluna da Universidade Sénior, voluntariado que já teve pelo menos três registos diferentes, além da atividade física que procura não dispensar. O tempo livre leva-a portanto a desfrutar dos equipamentos recentes no concelho, onde se incluem iniciativas que a mantêm ativa civicamente:

No dia a seguir a aposentar-me fui-me inscrever na piscina [...]. Depois encontrei a Universidade Sénior, na Ramada, onde tenho aulas. A partir daí participo em tudo o que posso. [...] Temos um grupo de voluntariado [...] para apoiarmos idosos [...] Fazia também até ao ano passado através da Junta de Freguesia da Ramada aulas de alfabetização [...] para idosos que não soubessem escrever, e para pessoas doutros países. E há um colega [...] que sempre sonhou em construir tertúlias em Odivelas. Pediu à Câmara, que aceitou e agora éjá uma organização fantástica. [...]. As tertúlias também organizam passeios ao longo do ano. [Maria, 65 anos, Odivelas, entrevista 05/05/2014]

Maria faria ainda mais coisas, sobretudo em termos de viagens, se não tivesse, nos últimos anos, de ajudar os filhos. A crise económica levou-a a prescindir de parte de serviços domésticos e de algumas viagens mais arrojadas com os amigos da Universidade Sénior. O retrato de Maria é por isso também um retrato da classe média portuguesa que perdeu poder de compra nos últimos anos face à crise económica, contrariando as suas expectativas no início de vida, quando imaginava que as coisas melhorariam sempre:

Eu reformei-me com um valor e neste momento estou com mil euros a menos. [...] A bola de pingue-pongue é muito pesada para nós. Batem-nos de um lado e de outro. [...] Há dias muito pesados. Mas aprendi a viver doutra maneira. O desemprego é um peso muito grande. O projeto de vida deles [filhos]... O meu projeto de vida... A pessoa formou-se, teve um emprego que até deu para escolher, não teve de trabalhar fora da área, ganho isto, posso fazer isto e aquilo, comprar um carro. E hoje em dia eles não podem ter esse projeto de vida. E se têm, estão a medo. [Maria, 65 anos, Odivelas, entrevista 05/05/2014]

\section{O empenhamento político e cultural de David}

Desde novo, David, hoje com 22 anos, envolveu-se em atividades desportivas, artísticas e políticas. Foi na Damaia, freguesia do concelho da Amadora, que viveu a infância e construiu amizades que até hoje perduram. Mudou-se com a família - pais e o irmão - para uma nova urbanização em Odivelas em 2005, motivados pela busca de melhor qualidade de vida. Esta mudança não impediu que David continuasse a 
frequentar a Damaia, principalmente após voltar para uma escola secundária daquela zona.

A crise económica mundial de 2008, cujos efeitos depressa se fizeram sentir em Portugal, foi particularmente ruinosa para David, tendo coincidido com a separação dos pais. O salário de professora da mãe passou a ter de assegurar a totalidade das despesas do agregado familiar, situação agravada pelo desemprego do pai e pelo pagamento ao banco do empréstimo da casa. A necessidade de reajustarem as despesas tornou David mais sensível aos problemas sociais e económicos. Não obstante, esta temática era próxima da vida de David. Desde criança que os pais o incentivaram a ter uma visão crítica sobre a sociedade, através de conversas quotidianas, e por via do estímulo às artes: literatura, cinema, teatro. Antigo militante do partido político União Democrática Popular (UDP), o seu pai costumava levá-lo às marchas do 25 de Abril e do $1 .{ }^{\circ}$ de Maio, momento em que vinham à tona ideologias e padrões culturais que valorizavam a ação coletiva, entendida como instrumento de transformação social. Como recorda David:

Eu sempre acompanhei o meu pai às marchas do 25 de Abril e do 1.ํ de Maio. Era quase um ritual... Ele muitas vezes ia encontrar-se com os antigos companheiros em almoços, e havia muita conversa e música de intervenção. $\mathrm{O}$ meu pai pôs-me em contacto com a música de intervenção desde pequeno. E isso, de alguma forma, despoletou a minha consciência. [David, 22 anos, Odivelas, entrevista 15/10/2014]

Após três anos numa escola em Odivelas, David optou por voltar a estudar na Damaia, para onde o seu pai regressou depois de se divorciar. Foi um período de intenso crescimento pessoal e experimentação. Participou em oficinas de teatro, organizou debates e foi responsável por editar um jornal escolar. A criação de uma lista para concorrer à associação de estudantes assinala um período em que se tornou ativo politicamente, mobilizando os amigos para o processo eleitoral. Venceram as eleições, o que lhes permitiu melhores condições para organizar atividades de interesse dos estudantes.

Houve dois momentos na vida de David que nos ajudam a compreender a sua imersão em práticas de ação coletiva de cariz artístico-cultural e político. O primeiro ocorreu no início do ensino secundário, quando participou numa mobilização estudantil. Por todo o país, os estudantes revoltavam-se contra as aulas de substituição e o fim das faltas justificadas. Ver os colegas fazerem um cordão humano para impedir que alunos e professores entrassem na escola e, posteriormente, seguir em protesto até à Assembleia da República foi um acontecimento que o marcou.

O segundo momento foi nas eleições legislativas de 2009, quando o pai se tornou um dos responsáveis pela campanha eleitoral do Bloco de Esquerda (BE) na Amadora. David acompanhou-o em atividades do partido, uma influência decisiva para o seu empenhamento político-cidadão. A filiação no BE surgiu naturalmente. Tornou-se militante, tendo participado como delegado no Congresso de Jovens do Bloco de Esquerda. Essa socialização política pô-lo em contato com múltiplos reportórios de ação coletiva, estimulando o David para o agir político. É nesse contexto de 
militância que surge a vontade de construir uma lista para a associação de estudantes na sua escola.

A entrada na licenciatura de Comunicação Social na Faculdade de Ciências Sociais e Humanas da Universidade Nova de Lisboa (FCSH-UNL) permitir-lhe-ia ampliar as experiências artísticas e políticas. Logo no 1.ำ ano integrou o grupo de teatro da faculdade e tornou-se um dos dinamizadores de uma lista para concorrer à associação de estudantes, continuando a participar em listas nos dois anos seguintes, e envolver-se-ia também com o universo audiovisual.

Integrar uma lista independente para concorrer à nova freguesia das Águas Livres nas eleições autárquicas de 2013 foi um importante momento na sua militância política. David foi um dos protagonistas dessa lista - Movimento Independente das Águas Livres (MIAL) - , pois conhecia muitos jovens que moravam naquela zona. Como refere:

O facto de conhecer bastante gente e ter feito lá intervenção, acabei por ser um dos candidatos deste movimento independente. [...] Durante a campanha tentámos falar com as pessoas, organizámos um debate com jovens, com amigos meus, e explicámos porque é preciso intervir, sem ficar a dizer "votem em mim de quatro em quatro anos". E tivemos resultados bastante positivos: conseguimos eleger uma pessoa para a freguesia. [David, 22 anos, Odivelas, entrevista 15/10/2014]

É interessante notar a centralidade das sociabilidades locais de David para a sua escolha enquanto segundo candidato da lista do MIAL. Não obstante a mudança para Odivelas, densas interações locais foram mantidas por David na Damaia, o que nos obriga a pensar as identidades locais de modo aberto em relação à circulação dos indivíduos. Assim, o aumento da mobilidade dos indivíduos não implica a fragmentação dos laços sociais, nem sequer um desenraizamento local (Carmo e Simões, 2009). Afinal, como refere David: "[...] do ponto de vista humano sinto-me melhor na Damaia porque tenho lá os meus amigos" [David, 22 anos, Odivelas, entrevista 15/10/2014].

Desde que iniciou o mestrado, a participação política perdeu o vigor de outrora: deixou de militar em partidos políticos e abandonou o movimento estudantil. Contudo, o empenhamento cívico continua, e interliga-se com o universo artístico-cultural de alguns dos seus projetos, como num documentário sobre habitação, nas atuações teatrais e nos textos jornalísticos. Na arte ou na política, a ação coletiva é parte integrante do percurso biográfico de David. Ambas as esferas estão implicadas em formas inovadoras de participação político-cidadã, e potenciam subjetividades alternativas que estão constantemente a conferir novos sentidos existenciais à vida de David.

\section{Conclusão}

A ação coletiva à escala individual é vivida em contextos de intensas sociabilidades, que de alguma forma alimentam as próprias razões para o agir coletivo. Por 
intermédio da análise efetuada, verifica-se que na maior parte dos entrevistados emerge a ligação mais ou menos identitária aos locais de residência (atuais e anteriores). Estes contextos locais são fundamentais para ancorar os envolvimentos associativos e políticos, onde se reconstroem e se reproduzem círculos sociais amicais, culturais-artísticos e institucionais.

Os retratos sociológicos de Luís, Maria e David permitem-nos perceber o modo como os contextos sociais e locais influenciam o seu percurso biográfico enquanto protagonistas de ação coletiva; que as socializações constituem matrizes indutoras de disposições sociais para a ação coletiva; e, finalmente, que se verificam determinadas lógicas de interação coletiva que são constantes nos percursos biográficos dos nossos entrevistados.

Luís, Maria e David representam três estudos de caso de residentes na AML, com trajetórias de vida diferenciadas entre si relativamente a estratégias migratórias, trajetórias de mobilidade residencial, condições e modos de vida, redes de sociabilidade, relação com o contexto local e inserção em atores coletivos.

Constituem trajetórias de ação coletiva multiparticipadas, atuantes em contextos de intervenção sindical, estudantil, cultural-artístico, associativo e em partidos e movimentos políticos. Trata-se de protagonistas de ação coletiva com forte inserção nos mais variados contextos locais no interior da área metropolitana de Lisboa.

As suas disposições para a ação coletiva exprimem os seus processos de socialização familiar, escolar, laboral, sociopolíticos e simbólico-ideológicos. Estamos perante indivíduos que partilham valores e universos simbólicos fomentadores de disposições ativas face às exclusões e às injustiças sociais. Acontecimentos marcantes na história coletiva e pessoal despoletam e justificam a sua ação coletiva, cujos habitus militantes se mobilizam face às desigualdades e às situações consideradas como injustas.

\section{Referências bibliográficas}

Bourdieu, Pierre (1997), Practical Reason. On the Theory of Action, Stanford, CA, Stanford University Press.

Burawoy, Michael (2015), "Facing an unequal world", Current Sociology, 63 (1), pp. 5-34.

Carmo, Renato Miguel do (org.) (2011), Entre as Cidades e a Serra. Mobilidades, Capital Social e Associativismo no Interior Algarvio, Lisboa, Editora Mundos Sociais.

Carmo, Renato Miguel do, e José Alberto Simões (orgs.) (2009), A Produção das Mobilidades, Redes, Espacialidades e Trajectos, Lisboa, Imprensa de Ciências Sociais.

Castells, Manuel (2012), Networks of Outrage and Hope. Social Movements in the Internet Age, Cambridge e Malden, Polity Press.

Coelho, Sandra Lima (2012), “A organização e os seus agentes: análise das trajetórias biográficas de voluntários de uma associação de Comércio Justo", em João Teixeira Lopes (org.), Registos do Ator Plural. Bernard Lahire na Sociologia Portuguesa, Porto, Edições Afrontamento, pp. 91-115. 
Costa, António Firmino da (1995), "Modes de vie et action collective", Espaces et Sociétés, 79, pp. 107-124.

Costa, António Firmino da (1999), Sociedade de Bairro. Dinâmicas Sociais da Identidade Cultural, Lisboa, Celta Editora.

Costa, António Firmino da (2007), “Os desafios da teoria da prática à construção da sociologia", em José Madureira Pinto e Virgílio Borges Pereira (orgs.), Pierre Bourdieu. A Teoria da Prática e a Construção da Sociologia em Portugal, Porto, Edições Afrontamento, pp. 15-29.

Costa, António Firmino da, João Teixeira Lopes, e Ana Caetano (orgs.) (2014), Percursos de Estudantes no Ensino Superior. Fatores e Processos de Sucesso e Insucesso, Lisboa, Editora Mundos Sociais.

Crossley, Nick (2002), Making Sense of Social Movements, Berkshire, Open University Press.

Crossley, Nick (2003), "From reproduction to transformation: social movement fields and the radical habitus", Theory, Culture E Society, 20 (6), pp. 43-68.

Edwards, Bob, e John McCarthy (2004), "Resource and social movement mobilization”, em David A. Snow, Sarah A. Soule e Hanspeter Kriesi (orgs.), The Blackwell Companion to Social Movements, Malden, MA, Blackwell Publishing, pp. 116-152.

Frazer, Nancy (2008), Scales of Justice, Cambridge, Polity Press.

Giugni, Marco (2004), "Personal and biographical consequences", em David Snow, Sarah A. Soule e Hanspeter Kriesi (orgs.), The Blackwell Companion to Social Movements, Malden, MA, Blackwell Publishing, pp. 489-503.

Habermas, Jürgen (1989), The Structural Transformation of the Public Sphere. An Inquiry into a Category of Bourgeois Society, Cambridge, Polity Press.

Kelly, Caroline, e Sara Breinlinger (1996), The Social Psychology of Collective Action, Bristol, Taylor \& Francis.

Klandermans, Bert, e Susan Staggenborg (orgs.) (2002), Methods of Social Movement Research, Minneapolis, University of Minnesota Press.

Klandermans, Bert, e Conny Roggeband (orgs.) (2007), Handbook of Social Movements Across Disciplines, Nova Iorque, Springer.

Lahire, Bernard (2002), Portraits Sociologiques. Dispositions et Variations Individuelles, Paris, Nathan.

Lahire, Bernard (2003), O Homem Plural. As Molas da Ação, Lisboa, Instituto Piaget.

Lahire, Bernard (2005), “Patrimónios individuais de disposições: para uma sociologia à escala individual", Sociologia, Problemas e Práticas, 49, pp. 11-42.

Lopes, João Teixeira (org.) (2012), Registos do Ator Plural. Bernard Lahire na Sociologia Portuguesa, Porto, Edições Afrontamento.

Lopes, João Teixeira (2014), “Retratos sociológicos: dispositivo metodológico para uma sociologia da pluralidade disposicional", em José Augusto Palhares, e Leonor Lima Torres (orgs.), Metodologia de Investigação em Ciências Sociais da Educação, Vila Nova de Famalicão, Edições Húmus, pp. 99-112.

Martin, Greg (2015), Understanding Social Movements, Londres, Routledge.

McAdam, Doug (1999), “The biographical impact of activism”, em Marco Giugni, Doug McAdam e Charles Tilly (orgs.), How Social Movement Matter, Minneapolis e Londres, University of Minnesota Press, pp. 119-146. 
McCarthy, John, e Mayer Zald (2001), “Resource mobilization theory: vigorous or outmoded?", em Jonathan Turner (org.), Handbook of Sociological Theory, Nova Iorque, Springer, pp. 533-565.

Mouzelis, Nicos (2008), Modern and Postmodern Social Theorizing, Cambridge, Cambridge University Press.

Nunes, Nuno (2013a), Desigualdades Sociais e Práticas de Ação Coletiva na Europa, Lisboa, Editora Mundos Sociais.

Nunes, Nuno (2013b), “Desigualdades sociais e ação coletiva nas sociedades contemporâneas: a fecundidade teórica de Pierre Bourdieu e de Nicos Mouzelis", Sociologia, 25, pp. 33-53.

Olson, Mancur (1998), A Lógica da Acção Colectiva. Bens Públicos e Teoria dos Grupos, Oeiras, Celta Editora.

Tilly, Charles (2006), Regimes and Repertoires, Chicago, The University of Chicago Press.

Touraine, Alain (1998), Pourrons-Nous Vivre Ensemble?, Paris, Editions Fayard.

Van Stekelenburg, Jacquelien, e Bert Klandermans (2007), “Individuals in movements: a social psychology of protest", em Bert Klandermans, e Conny Roggeband (orgs.), Handbook of Social Movements Across Disciplines, Nova Iorque e Amesterdão, Springer, pp. 157-204.

Velho, Gilberto (1994), Projeto e Metamorfose. Antropologia das Sociedades Complexas, Rio de Janeiro, Jorge Zahar Editor.

Wieviorka, Michel (2012), "The resurgence of social movements", Journal of Conflictology, 3 (2), pp. 13-19.

Nuno Nunes (corresponding author). Investigador do Centro de Investigação e Estudos de Sociologia (CIES), ISCTE - Instituto Universitário de Lisboa, Av. das Forças Armadas, 1649-026 Lisboa, Portugal. E-mail: nuno.nunes@iscte.pt

Rita Ávila Cachado. Investigadora do Centro de Investigação e Estudos de Sociologia (CIES), ISCTE - Instituto Universitário de Lisboa, Av. das Forças Armadas, 1649-026 Lisboa, Portugal. E-mail: rita.cachado@iscte.pt

Otávio Raposo. Investigador do Centro de Investigação e Estudos de Sociologia (CIES), ISCTE - Instituto Universitário de Lisboa, Av. das Forças Armadas, 1649-026 Lisboa, Portugal. E-mail: otavio_raposo@iscte.pt

Daniela Ferreira. Investigadora do Centro de Investigação e Estudos de Sociologia (CIES), ISCTE - Instituto Universitário de Lisboa, Av. das Forças Armadas, 1649-026 Lisboa, Portugal. E-mail: daniela.alexandra.ferreira@iscte.pt 
Renato Miguel do Carmo. Investigador do Centro de Investigação e Estudos de Sociologia (CIES), ISCTE - Instituto Universitário de Lisboa, Av. das Forças Armadas, 1649-026 Lisboa, Portugal. E-mail: renato.carmo@iscte.pt

Receção: 08 de agosto de 2015 Aprovação: 12 de novembro de 2016 
